\title{
Mathematical modeling evaluation for convective hot air drying of poultry meat
}

JAVEED AKHTAR AND P.K. OMRE

Received : 24.02.2017; Revised : 18.03.2017; Accepted : 26.03.2017

See end of the Paper for authors' affiliation

Correspondence to :

JAVEED AKHTAR

Department of Post Harvest

Process and Food

Endineering, College of

Technology, G.B. Pant

University of Agriculture and

Technology, Pantnagar, U.S.

NAGAR (UTTARAKHAND)

INDIA

$\underline{\text { Email : er.jakhtar@gmail.com }}$
- ABSTRACT : The aim of this study is to determine drying behaviour of different two type chicken meat samples at five temperatures $\left(45,55,65,75\right.$ and $\left.85^{\circ} \mathrm{C}\right)$, five air velocities $(2.5,3.5,4.5$, 5.5 and $6.5 \mathrm{~m} / \mathrm{s})$ and three thicknesses $\left(1 \mathrm{~cm}^{3}, 1.5 \mathrm{~cm}^{3}\right.$ and $\left.2 \mathrm{~cm}^{3}\right)$ in high velocity hot air dryer for manufacturing of dried chicken meat product. Only falling-rate period was observed for both of the dried meat samples. The five empirical models namely page's, Logarithmic, Exponential, two term exponential and Henderson and Pabis were fitted to experimental moisture ratio data. These models were tested in MATLAB software version R2013a using curve-fitting tool box with nonlinear method of Levenberg-Marquartd algorithm. Performance of five drying models was evaluated on the basis of co-efficient of determination $\left(\mathrm{R}^{2}\right)$, standard error estimation (SEE) and root mean square error (RMSE)by using nonlinear regression analysis. Page's model gave better prediction for moisture ratio.

- KEY WORDS : Mathematical modelling, Meat drying, Poultry meat, MATLAB

- HOW TO CITE THIS PAPER : Akhtar, Javeed and Omre, P.K. (2017). Mathematical modeling evaluation for convective hot air drying of poultry meat. Internat. J. Agric. Engg., 10(1) : 168-178, DOI: 10.15740/HAS/IJAE/10.1/168-178. 